\title{
CHALLENGE THYROIDECTOMY MANUAL DELIVERY VERSUS STERNOTOMY IN RETROSTERNAL GOITER
}

\author{
By \\ YASSER AHMED EL SAYED ${ }^{1}$, YASSER MOHAMED \\ SHAFIK ${ }^{2}$ AND EISSA ABDEL-HAMED IBRAHIM ${ }^{3}$ \\ Consultant of Thoracic Surgery ${ }^{1}$ Consultant Anesthesia and Pain Management ${ }^{2}$ and \\ Consultant General Surgery ${ }^{3}$, Military Medical Academy, Cairo, 11291, Egypt \\ $\left({ }^{*}\right.$ Correspondence: ${ }^{1}$ yasser.elsaid31@yahoo.com, ${ }^{2}$ yaser0002002@yahoo.com, \& \\ 3eissaabdlhamed@gmail.com,)
}

\begin{abstract}
The study was carried out on 40 patients presented with thyroid swelling admitted at Kobry El-Kobba Military Medical Compass over two years. Eighteen of them suffered from retrosternal goiter and were divided into two groups. GI: 4 males were treated by sternotomy and total thyroidectomy, which histopathological examination showed multinodular goiter. GII: 14 patients ( 12 males $\& 2$ females) were treated by cervical incision and manual retrosternal goiter deli- very. Patients in both groups were followed up 2 weeks over three months and then one month over a year post-operation for thyroid profile, serum Ca level, and histopathological specimens showed multinodular goiter without malignancy.

In GI, one patient developed wound secondary infection and was treated by antibiotic. Another one showed post-operative hypocalcemia and was treated by oral vitamin D and Ca 500 $\mathrm{mg}$ and improved after 6 months. In GII, six male patients showed complications; two showed transient hypocalcemia post-operative and were treated by I.V. Ca gluconate $10 \%$ every $12 \mathrm{hr}$ for 2 days followed by oral Ca every $12 \mathrm{hr}$ for another week and then one vitamin D and one $\mathrm{Ca}$ - tablet for 6 months. One patient showed neck hematoma and exploration was done to evacuate hematoma and bleeding control. Two patients showed nerve problem in the form of voice change, difficult in swallowing and aspiration. One was managed by endotracheal intubation for $48 \mathrm{hr}$ and the second was managed by Oxygen therapy and steroid. One patient showed mild infection and skin edema that was managed by antibiotic and anti-edematous agent. The last one showed sinus formation and was treated by curettage and antibiotic. The hospital stay was long in GI than in GII, as in GI $48 \mathrm{hr}$ ventilation used post-operative compared to 24hr in GII, but neither tracheomalacia treatment nor tracheostomy in both groups.
\end{abstract}

Keywords: Retrosternal goiter, Thyroidectomy, Sternotomy, Manual delivery.

\section{Introduction}

The goiter or goitre is the Latin word "tamadun gutters" gutter-throat or thyroid gland increased to twice size or heavier than 40 gm and treated according to cause (Huin et al, 2008).

If the thyroid gland produced an excess of thyroid hormones (T3 \& $\mathrm{T} 4$ ), radioactive iodine was given to patient to shrink gland (Markou et al, 2001). More than $90 \%$ of goitre cases resulted from iodine deficiency and small doses of Lugol's iodine or KI solution were given (Calissendorff and Falhammar, 2017). If the goiter was associated with an underactive thyroid, thyroid supplements were used, but a partial or complete thyroidectomy was indicated (Gandolfi et al,
2004).

The causes of enlarged thyroid gland, hypothyrodism, iodine deficiency in diet, increased thyroid stimulating hormone and much pathology may cause thyroid gland enlargement. Cervical goiters were $85-90 \%$ \& intrathoracic region 10-15\% (Vaiman and Bekerman, 2017). Retrosternal goiter (RSG), defined by different classification was with incidence of $2 \%$, and $26 \%$ of all thyroidectomy patients (Perincek et al, 2018).

Goncolves and Kowalski (2005) reported that the substernal goiter was first described in 1749 , as the thyroid tissue extension below upper opening of the chest. This concept was controversial but without a single definition today (Sakkary et al, 2012). 
A retrosternal goiter is an anatomical entity and not a pathological one, with 3 variants: substernal or retrosternal extensions of large goiter common due to pretracheal muscles push on thyroid, helped by negative intrathoracic pressure directed goiter within a false capsule backwards \& downwards into superior mediastinum. Plunging goiter appeared intermittently intrathoracic in neck on cough, intrathoracic or mediastinal goiter.

Generally, thyroid gland is the first developed endocrine gland during fetal embryology, between third and fourth gestational weeks. Its primary origin is the endoderm, which gave rise to the median, and the two lateral analogues contained c-cells, solid nests cells and portions of the lateral thyroid. Thyroid failure descends from the thyroid region to its final location in front of the trachea is an ectopic thyroid presented at any position from the foramen caecum at the tongue base to the mediastinum (Alanazi and Limaiem, 2020). Retrosternal, substernal and intrathoracic goiter is a subgroup of multinodular goiter (MNG). The MNG patients' encountered in surgical practice by ultrasound scanning (USS) was between 10 $\& 20 \%$ and by high resolution USS reached up to $70 \%$. Most of them cured with total lobectomy or total thyroidectomy that minimized recurrence rates and ensured an oncological approach to patients with incidentally discovered malignancy within MNG (Nixon and Simo, 2013). In non-iodine deficient patients, ultrasound detected thyroid nodules in $>20 \%$ of people, and multiple nodules in $>9 \%$ in females and in older patients (Popoveniuc and Jonklaas, 2012). But, difference in the risk of thyroid malignancy for patients with multinodular goiter (MNG) and solitary nodular goiter (SNG) was controversial.

Multinodularity did not increase the thyroid malignancy risk and patients with MNG who develop papillary carcinoma increased the risk of cancer multimodality (Lin et al, 2016). Thyroid nodules were common and need to assess thyroid function, degree of and future risk of mass effect, and exclude thyroid cancer, which occurred in $7-15 \%$ of thyroid nodules (Wong et al, 2018).

This study aimed to demonstrate challenge thyroidectomy; manual delivery versus sternotomy in retrosternal goiter among 18/40 inpatients at Kobry El-Kobba Military Medical Campus.

\section{Material and Methods}

A total of 40 patients underwent surgical treatment for goiter at Kobry El-Kobba Military Medical Campus. Thyroidectomy for retrosternal "retrosternal extension of thyroid gland" goiter was done in $18 / 40$ patients. They were 2 females and 16 males (14 military and 4 civilian) with a mean ages ranged from 50 to 65 years. Patients were divided into 2 groups. GI: 4 male patients treated by sternotomy and total thyroidectomy. GII: 14 patients treated by total thyroidectomy via cervical incision and manual delivery of goiter retrosternal extension (Tab.1)

Ethical considerations: All patients were informed about their surgical indication, and operation was done after obtaining a written consent from them and investigation done to all patients.

By neck clinical examination for thyroid gland was not enlarged, but there was a plugging swelling at supra-sternal notch during swallowing. Clinical suspicion was evaluated by physical examination \& chest X-ray that showed tracheal deviation and mediastinal mass (Fig. 1). Thyroid status was confirmed by: a- Neck US, b- Neck and chest $\mathrm{CT}$ for all patients suspected for retrosternal goiter and planned for surgery, Thyroid extension into mediastinum and tracheal deviation were seen in all patients. cThe mediastinal soft tissue mass isotope scan proved the diagnosis and excluded malignancy (Fig. 3). Some patients were presented by chest pain and CT coronary angio revealed coronary lesion (Fig. 4a \& b). Patients diagnosed to have retrosternal goiter. Pre-operative evaluation done as follows: 1- Careful assessment of general surgery fitness as many patients were elder; electro- 
cardiography, echocardiography, CT coronary ango and pulmonary function assessment were considered in those needed sternotomy, especially with significant cardiorespiratory diseases.

2-Assessment of thyroid malignancy: Full clinical examination of head and neck for cervical lymphadenopathy and US assessed central and lateral neck triangle, and guided fine needle aspiration cytology and tumor marker, as calcitonin, LDH, thyroglobulin thyroid \& parathyroid function assessment, in hyperthyroid patient treated by beta blocker i.e. Inderal $40-80 \mathrm{mg} /$ day until tachycardia controlled and prevention of thyrotoxic crisis during \& after surgery.

3- Assessment of vocal cord functions by indirect or direct laryngoscopy in awake patients to determine the RLN function to minimize the postoperative possible airway compromise.

4- In strider patients, the tracheal image was done to determine tracheal compression, site and narrowing length; an AP X-ray gave dependable indication, CT, or MRI showed the relationship of I.G to trachea, esophagus and great vessels.

5- Coagulation status to exclude bleeding and coagulation disorder, $\mathrm{CBC}$, liver function tests and enzymes, renal function tests, and blood sugar level.

6- Once patient diagnosed IG and surgery indicated multidisciplinary meeting done, and the clinical team included expert thyroid surgeon, thoracic surgeon for sternotomy and anesthesia specialist in monitoring of recurrent laryngeal nerve to reduce palsy rates and awareness of presence, degree and level of tracheal compression.

The GI patients suffered from giant retrosternal extension were treated by sternotomy and total thyroidectomy \& GII was treated by the cervical Kocher's incision and total thyroidectomy.

Surgery GI: There was indication of cervical incision and sternotomy due to difficultly in delivering thyroid via thoracic inlet. So, general endotracheal anesthesia spine posi- tion with neck extension was done (Fig. 5). Complete exposure of chest and prepared neck to umbilicus and axilla to axilla by painting the skin by antiseptic (povidone-iodine) and draping the patient.

Generous lower neck Kocher incision was placed midway between the cricoid cartilage and supra-sternal notch extended in the skin to the anterior border of trapezius muscle.

Elevation of sub-platysma flaps, laterally up to trapezius muscle and inferior to the cervical and the sternal notch to allow assessing the goiter and thoracic inlet. After incision of investing fascia of neck, the strap muscle retracted laterally in large goiter the strap muscle was divided for better visualizing the anatomical structures that was preserved to deliver the thyroid gland from thoracic inlet, and sternotomy was done (Fig. 6). Sternotomy and mediastinal exposure stage: 1- A midline incision from cervical wound to the xiphisternum level in a T-fashion, 2- Suprasternal ligament divided with electrocautery, 3- Incise the subcutaneous fat down to sternal periosteum, 4- Identify midline superiorly at sternal notch, inferiorly at xiphisternum level, 5- A linear incision in the sternal periosteum in the midline, 6- Blunt dissection with a finger and sweep retrosternal at the top and bottom end of sternum to expose and prepare a space for the path of the saw, and 7- Insertion of a Holmes-sellors retractor to expose the mediastinum (Fig. 7a, b \& c).

The mediastinum was inspected to clarify goiter location and extent and to identify the mediastinal vessels controlled commence. Dissection in an extracapsular plane from anterior to inferior, ligation any extracapsular vessels were encountered, with careful dissection of recurrent laryngeal nerve and parathyroid gland from the gland "cervical part" (Fig. 8a \& b).

Dissections of gland were done in all direction i.e. posterior, laterally and deliver the gland in an upward until thoracic inlet_(Fig. 9). Thyroid bed was inspected and mediastinal cavity for bleeding and achieve hemosta- 
sis and ensure no mediastinal structures were inadvertently be injured (Fig. 10). After complete mobilization of gland from mediastinum anterior, lateral and posterior dissection was done. The gland at the thoracic inlet was carefully dissected and de- vascularized by ligation of middle thyroid vein, inferior thyroid artery and superior thyroid artery (Fig. 11a \& b).

When thyroidectomy was completed, the wound was washed by warm saline solution; hemostasis was achieved insertion of 2 suction drains (Redivac), one in mediastinum and one in thyroid bed in neck. Close the sternum by titanium wires and closure the skin of sternum and skin of cervical incision by metallic staples after closure subcutaneous tissue in sternal incision and platysma in neck incision (Fig. 13a, b \& c).

Thyroid gland and mass were examined macroscopically from anterior aspect and from posterior aspect, anterior aspect of the asthmas, right lobe, left lobe, showing smooth surface and mass originated from lower part of left lop and posterior surface of mass showed discontinuity of its capsule due to manual manipulation to deliver gland from thoracic inlet, and histopathological examination showed multinodular goiter without malignancy in all patients (Fig. 14a \&b).

Postoperative: 1- Patients were admitted to ICU for ventilation and was off after 2 days, 2- IV fluid, antibiotic and analgesic, 3-Anticoagulant, drain removed 5 days and clips 10 to 15 days and follow up in outpatient cli- nic, 4- Ca gluconate IV to manage any hypocalcemia.

Surgery GII: Cervical Kocher's incision and manual delivery of retrosternal extension were done.

Cervical stage:1- General endotracheal anesthesia and patient in spine position, 2Lower cervical collar Kocher's incision (Fig. 16), 3- Elevation of sub-platysma flap and manual retrosternal delivery (Fig. 17), 4Mobilization and de-vascularization of gland was done with parathyroid gland preservation and recurrent laryngeal nerve (Fig. 18), 5- Good hemostasis, inspection of retrosternal space and insertion of hemostatic agent, i.e., absorbable fibrillar (Fig. 19), 6- Insertion of suction drain (Redivac) and closure of wound in layer, approximation of strap muscle, closure of platysma and subcutaneous and closure of skin by metallic staple as in GI, 7- Macroscopic examination of specime-ns showed multi nodular surface, intact cap- sule, 8- Right lobe, left lobe, isthmus and el-evator thyroid glandule (remint part of obliterated thyroglossal duct) and microscopic examination showed multinodular goiter (Fig. 20).

\section{Results}

All patients had bilateral multi-nodular goiter underwent total thyroidectomy post-operative pathologically showed multiple nodular goiter, without malignancy. Only four patients required full sternotomy \& 14 did not required and procedure was done via neck incision. The details were given in tables $(1,2 \& 3)$ and figures ( 1 to 20).

Table 1: Clinical findings among groups

\begin{tabular}{|l|l|l|}
\hline \multicolumn{1}{|c|}{ Variants } & \multicolumn{1}{c|}{ GI } & \multicolumn{1}{c|}{ GII } \\
\hline Symptoms and sign & 4 male patients & 14 patients (12 males, 2 females) \\
\hline Dyspnea & All patients & 8 patients \\
\hline Dyspnea & All patients & 5 patients \\
\hline Dyspnea and dysphagia & All patients & 3 patients \\
\hline RLN affection (voice change) & No voice change & 3 patients \\
\hline $\begin{array}{l}\text { Facial edema \& dilated vein on chest wall } \\
\text { and arm }\end{array}$ & $\begin{array}{l}2 \text { patients with facial edema } \\
1 \text { patient with dilated vein on chest }\end{array}$ & $\begin{array}{l}\text { No facial edema } \\
1 \text { patient dilated vein on chest }\end{array}$ \\
\hline Chest pain & 2 patients & 6 patients \\
\hline
\end{tabular}

Table 2: variations between both groups

\begin{tabular}{|c|c|c|}
\hline Variants & GI & GII \\
\hline Number & 4 & 14 \\
\hline Sex & All males & 12 males \& 2 females \\
\hline Ages & 55-65years average 60 & 45-55 years average 50 \\
\hline
\end{tabular}


Table 3: Represent post-operative follow up and complication

\begin{tabular}{|l|l|l|}
\hline Variants & GI & GII \\
\hline Hospital stay & $4-10$ days & $3-5$ days \\
\hline Ventilation support & All 1-2 days postoperative sternotomy & One case ventolatory due to neuropraxia of RLN \\
\hline Wound infection & One case & 3 cases mild wound infection \&1 with sinus formation \\
\hline Hypocalcema & One case & 2 males \\
\hline Bleeding & None & One case showed hepatoma evacuation done \\
\hline Nerve problem & None 2:1- managed by endotracheal entubation \& 1 by steroid + oxygen \\
\hline
\end{tabular}

Discussion

In Egypt, Elebrashy et al. (2016) reported that thyroid disease was more common in Egyptian women with type 2 diabetes than nondiabetic ones, due to a role of autoimmunity in the pathogenesis of type 2 diabetes. Fayed et al. (2019) reported thyroid disorder was related mainly to thyroid autoimmunity independent of age, sex, or HCV level of viremia. Saqre et al. (2019) reported that autoimmune thyroiditis was frequent among young female patients with rheumatoid arthritis.

In the present study, patients $35-45 \%$ of $18 / 40$ showed mass in retrosternal region. Vaiman and Bekerman (2017) reported that about $85-90 \%$ of the enlarged thyroid glands appeared as a mass that pressed the cervical region and about $10-15 \%$ of them appeared as a mass pressed the retrosternal region.

In the present study, the retrosternal goiter patient were presented by symptoms at late age, between 50 or 60 years or more, asked medical advice when they complained from dyspnea, dysphagia or both and chest pain but without neck mass in all. Two patients in GI and six in GII suffered mainly from chest pain and by $\mathrm{CT}$ coronary angio diagnosed coronary heart lesions.

In the present study, sternotomy incidence was $22.2 \%$ in large size goiter with difficult to deliver it through thoracic inlet. Grainger et al. (2005) in United Kingdom reported that substernal goiter patients were resected via one neck incision for sternotomy and thoracotomy ranged between $0 \%$ and $13 \%$. No doubt, the thoracic approach was commonly required in certain subsets of patients with a mediastinal thyroid mass. Monchik and Materazzi (2000) in USA reported that surgeons should be prepared for the increased likelihood of a thoracic approach in patients with malignant mediastinal tumors, or undergoing re-operative thyroid surgery, or with posterior or aberrant mediastinal thyroid masses. Flati et al. (2005) in Italy reported that in chest thyroid $>70 \%$ thoracotomy was inevitable. Nistor et al. (2014) in Romania reported that cervico-mediastinal thyroid mass with or without respiratory distress required a surgical excision as the only treatment option, and procedure represented a milestone for both anesthesiologist (difficult intubation in some large goiters cases) and thoracic surgeon. Coskun et al. (2014) in Turkey reported that goiter extension below aortic arch, large thyroid tissue extended towards tracheal bifurcation, and ectopic thyroid tissue in mediastinum indicated sternotomy and the substernal goiter might be removed via a cervical incision, but on rare occasions, a median sternotomy may be required. Amore et al. (2018) in Italy reported that most intrathoracic goiters were located in anterior mediastinum, and recommended surgical resection in case of morbidity associated with goiter's mass effect or for suspicion of malignancy difficult in diagnosis without resection.

In the present study, no malignancy was detected among all the patients. Winbladh and Järhult (2008) in Sweden found that in retrosternal goiters and carcinoma development as 1.3-3.7/1000patients. Takano (2017) in Japan reported that thyroid cancers have long been considered to arise in middle age and, after repeated proliferation, resulted in damage to genome, and progress to more aggressive and lethal cancers.

Ignjatović et al. (2002) classified goiters into cervical, retrosternal, substernal and intrathoracic. Huins et al. (2008) gave a new classification for retrosternal goiter; grade 1, above aortic arch above T4 with cervical ap- 
proach, grade 2, aortic arch to pericardium with manubriotomy, and grade 3 , below right atrium with full sternotomy.

\section{Conclusion}

The RSG was time consuming to induce compressive symptom, so treatment of asymptomatic RSG is one of controversies in surgical management. The total thyroidectomy was done for all patients with retrosternal goiter who did not have co-morbidity excluding them from surgery.

CT scanning is good tool in classification and approach for RSG cervical, full sternotomy or manubriotomy.

Level 1 was treated by cervical approach, but levels $2 \& 3$ by manubriotomy or full sternotomy and operation was done with a multidisciplinary team included thoracic, cardiothoracic surgeons experience in thyroid surgery and specialist anesthesia.

\section{Recommendations}

1- Total thyroidectomy in RSG and sternotomy in big size and grade 3 RSG to gain adequate exposure allowed delivery of intact gland, with minimal morbidity.

2- Replacement therapy started after histopathological diagnosis.

3- Cervical approach is successful in the maximum number of the present cases.

\section{References}

Alanazi, SM, Limaiem, F, 2020: Ectopic Thyroid. In: StatPearls [Internet]. Treasure Island (FL): StatPearls Publishing; Free Bo-oks \& Documents Bookshelf ID: NBK 539892.

Amore, D, Cicalese, M, Scaramuzzi, R, Natale, D, Curcio, C, 2018: Antero mediastinal retrosternal goiter: surgical excision by combined cervical and hybrid robot-assisted approach. J. Thorac. Dis. 10, 3:E199-202

Calissendorff, J, Falhammar, H, 2017: Lugol's solution and other iodide preparations: Perspectives and research directions in Graves' disease. Endocrine 58, 3:467-73.

Coskun, A, Yildirim, M, Erkan, N, 2014: Substernal goiter: when is a sternotomy required? Inter. Surg. 99:419-25.

Elebrashy, IN, Meligi, A, Rashed, L, Sa-lam, RF, et al, 2016: Thyroid dysfunction among type 2 diabetic female Egyptian subjects. Ther. Clin. Risk. Manag. 12:1757-62
Fayed, A, Soliman, A, Naguib, M, Ali, HM, Elhaddad, H, 2019: Thyroid dysfunction in Egyptian patients with hepatitis $C$ virus: Prevalence and possible triggering. Egypt. J. Inter. Med. 31, 4:678-82

Flati, G, De Giacoma, T, Porowska, B, Flati, D, Gaj, F, et al, 2005: Surgical management of substernal goiters when sternotomy inevitable. Clin. Ter. 156:191-5.

Gandolfi, PP, Frisina, A, Raffa, M, Renda, F, Rocchetti, O, et al, 2004: The incidence of thyroid carcinoma in multinodular goiter: retrospective analysis. Acta Bio-Med. 75, 2:114-7.

Goncolves, FG, Kowalski, LP, 2005: Surgical complications after thyroid surgery performed in a cancer hospital. Otolaryngol. Head Neck Surg. 132: 490-4.

Grainger, J, Saravanappa, N, D'souza, A, Wilcock, D, Wilson, PS, 2005: The surgical approach to retrosternal goiters: the role of computerized tomography. Otolaryngol. Head Neck Surg. 132: 849-51.

Huins, CT, Georgalas, C, Mehrzad, H, Tolley, NS, 2008: A new classification system for retrosternal goitre based on a systematic review of its complications and management. Inter. J. Surg. 6:71-6.

Ignjatović, M, Stanić, V, Cuk, V, Kostić, Z, 2002: Intrathoracic goiter: Analysis of 21 cases. Acta Chir. Iugosl. 49, 1:15-25

Lin, YS, Wu, HY, Yu, MC, Hsu, CC, Chao, TC, 2016: Patient outcomes following surgical management of multinodular goiter: Does multinodularity increase the risk of thyroid malignancy? Medicine (Baltimore) 95, 28:e4194.

Markou, K, Georgopoulos, N, Kyriazopoulou, V, Vagenakis, AG, 2001: Iodine-induced hypothyroidism. Thyroid 11, 5:501-10

Monchik, JM, Materazzi, G, 2000: The necessity for a thoracic approach in thyroid surgery. Arch. Surg. 135:467-72.

Nixon IJ, Simo, R, 2013: The neoplastic goitre. Curr. Opin. Otolaryngol. Head Neck Surg. 2:143-9.

Nistor, C, Ciuche, A, Motaş, C Motaş, N Bluoss, C, 2014: Cervico-mediastinal thyroid masses: Our experience. Chirurgia (Bu-cur) 109, 1: 34-43.

Perincek, G, Avci, S, Celtikci, P, 2018: Retrosternal goiter: A couple of classification methods with computed tomograpy findings. Pak. J. Med. Sci. 34:1494-9.

Popoveniuc, G, Jonklaas, J, 2012: Thyroid 
Nodules. Med. Clin. North. Am. 96, 2:329-49.

Sakkary, MA, Abdelahman, AM, Mostafa, AM, Abbas, AA, Zedan MH, 2012: A new classification system for retrosternal goiter based on a systematic review of its complications and management. J. Egypt. Notl. Canc. Inst. 24:8590.

Saqre, IM, El-Bahnasawy, AS, Farag, S M, Bazeed, FB, 2019: Autoimmune thyroid disease in Egyptian patients with rheumatoid arthritis. Egypt. Rheumatologist 41, 3:167-171.
Takano, T, 2017: Natural history of thyroid cancer: Review. Endocr. J. 64, 3:237-244.

Vaiman, M, Bekerman, I, 2017: Anatomical approach to surgery for intrathoracic goiter. Eur. Arch. Oto-Rhino-Laryngol. 274:1029-34.

Winbladh, A, Järhult, J, 2008: Fate of the nonoperated, non-toxic goitre in a defined population. Br. J. Surg. 95:338-43.

Wong, R, Farrell, SG, Grossmann, M, 2018: Thyroid nodules: diagnosis and management. Med. J. Aust. 209, 2:92-8.

\section{Explanation of figures}

Fig. 1: Chest X-ray showing deviation of trachea and wide upper mediastinum.

Fig. 2: CT neck and chest showed soft tissue mass and displacing mediastinal structure. Fig. 3: Thyroid isotope scan confirmed diagnosis and excluded malignancy.

Fig. 4: CT coronary angio in some retrosternal goiter patients (lesion in coronary artery) Fig. 5: Spine position with endo tracheal entubation. Fig. 6: Lower neck Kocher incision, subplatysmal flaps, and retraction of strap muscle laterally.

Fig. 7: a- Division of supra-sternal ligament, b- linear incision of sternum in midline by saw, c-insertion of chest retractor. Fig. 8: Inspection of mediastinum dissection of thyroid gland from mediastinal structure especially, pericardium.

Fig. 9: Deliver the gland up to thoracic inlet and back its bead.

Fig. 10: Washing bead of gland and examination of bead gland after removal for bleeding and mediastinal injury. Fig. 11: a- ligation of inferior thyroid artery, b- ligation of superior thyroid artery

Fig. 12: a- Recurrent laryngeal nerve, b- Parathyroid gland.

Fig. 13: a- closure of sternum by titanium wires, b- insertion of 2 radivac and closure of subcutaneous tissue, c-platesma and closure of skin by metallic clips.

Fig. 14: A thyroid and its mass from anterior aspect, B, posterior aspect showed discontent of its capsule. Fig. 15: General endo-tracheal anesthesia and spine position.

Fig. 16: Lower cervical Kocher's incision.

Fig. 17: Manual delivery of retrosternal goiter. Fig. 18: De-vascularization of gland.

Fig. 19: Surgical fibrillar in thyroid gland bead.

Fig. 20: Specimens, A, anterior aspect, B, posterior aspect, C, another one.

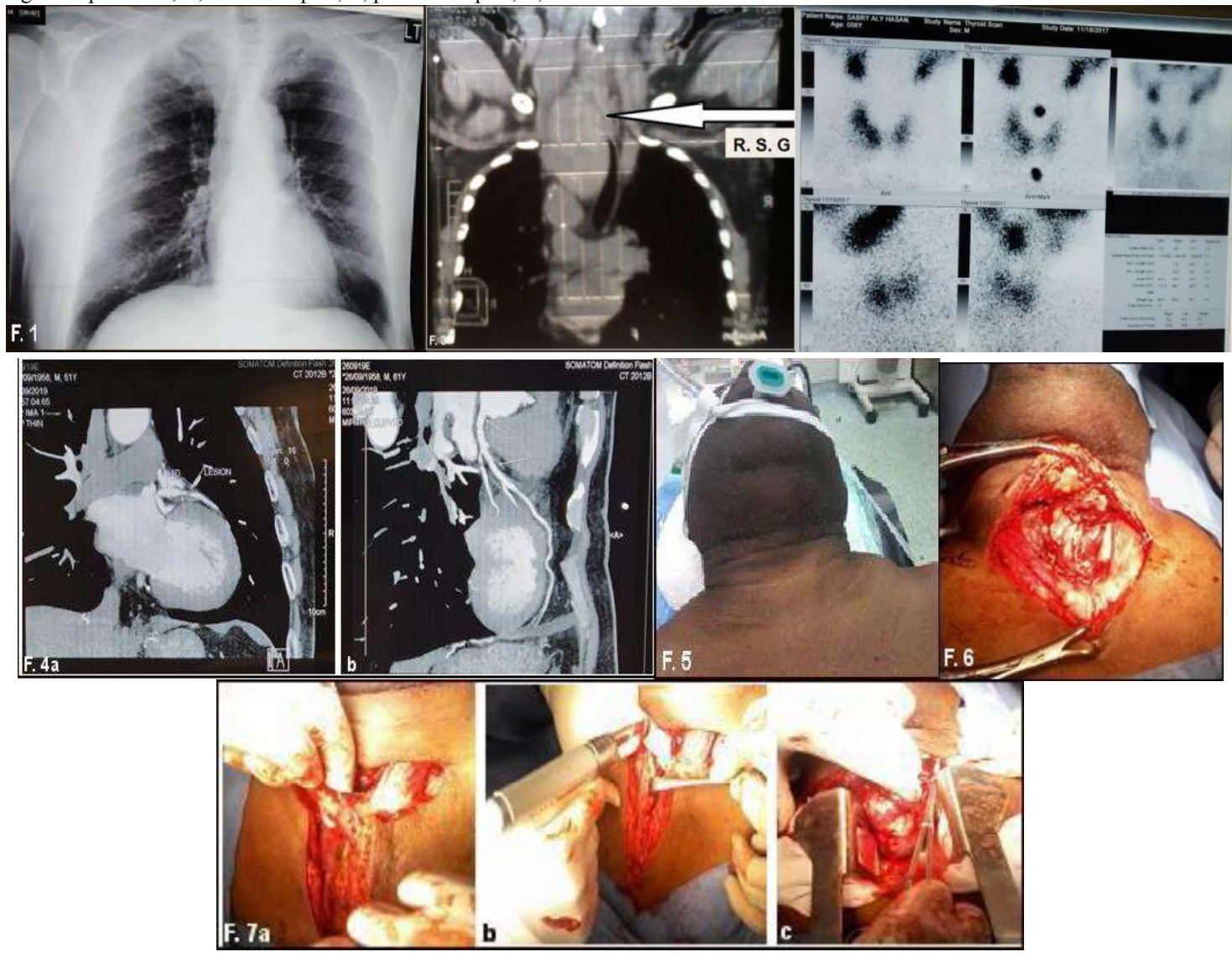




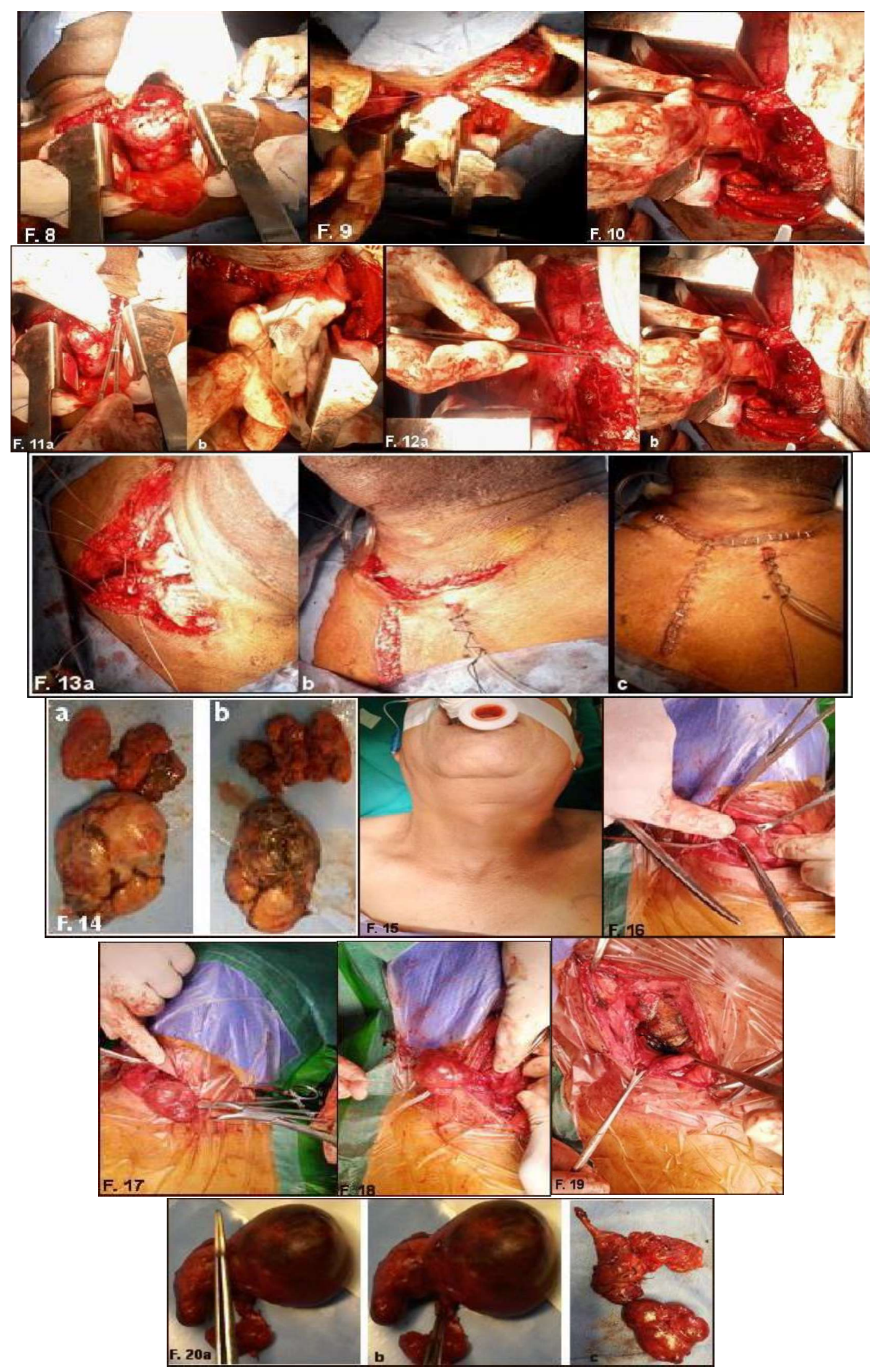

